\title{
Treatment of HCV Genotype-1a Infection with Sofosbuvir/ Daclatasvir in a Child Suffering from Thalassemia-Major
}

\author{
Hafiz Javed Mansoor ${ }^{1,2,4, *}$, Muhammad Salman Walayt ${ }^{1}$, Hammad Ahmed ${ }^{2}$, Mahtab Ahmad Khan ${ }^{3}$, \\ Muhammad Saeed ${ }^{4, *}$ \\ ${ }^{1}$ Mughal Medical Centre, Mughal Eye Hospital, JoharTown Lahore, Pakistan. \\ ${ }^{2}$ Faculty of Pharmacy, The University of Lahore-Lahore Pakistan. \\ ${ }^{3}$ Faculty of Pharmacy, The University of Central Punjab, Lahore Pakistan. \\ ${ }^{4}$ Department of Chemistry and Chemical Engineering, Syed Babar Ali School of Science and Engineering, \\ Lahore University of Management Science, Lahore, Pakistan.
}

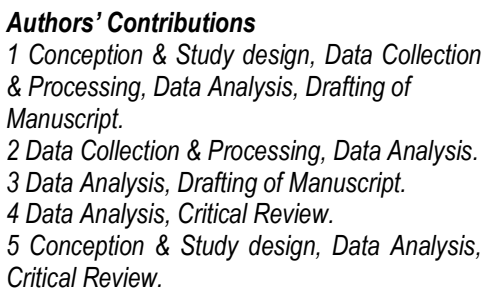

\section{Acknowledgement}

We would like to thank the Chairman and administrator of Mughal Medical Centre, who provided us with an excellent opportunity to conduct this research. We would also like to thank the doctors of Sundas Foundation for following-up with the patient regularly.

Article info.

Received: September 28, 2020

Accepted: December 21, 2020

Funding Source: Nil

Conflict of Interest: Nil

Cite this article: Mansoor HJ, Walayt MS Ahmed $H$, Khan MA, Saeed M. Treatment of HCV Genotype-1a Infection with Sofosbuvir/ Daclatasvir in a Child Suffering from Thalassemia-Major. RADS J Pharm Pharm Sci. 2020; 8(3):168-172.

*Address of Correspondence Author: hjmansoor@gmail.com

Muhammad.saeed@lums.edu.pk

\section{A B STR ACT}

Background: Beta thalassemia is the most common genetically transmitted disorder throughout the world. The life of a thalassemia patient depends on continuous blood transfusions, that can lead to various blood-borne viral infections mainly human immunodeficiency virus (HIV), hepatitis B virus (HBV), and hepatitis C virus (HCV) infections. Nevertheless, HCV infection is the most prevalent among blood transfusion-related blood-borne infections. Co-occurrence of thalassemia major with hepatic fibrosis,severe anemia, and iron over-load complicates HCV treatment. Additionally, treatment of HCV infection generally results in the manifestation of several drug-associated side effects, and the burden of continuous blood transfusions makes the condition worse.

Aim: Efficacy and safety of Sofosbuvir/ Daclatasvir in a HCV infected child suffering from thalassemia major.

Method: The patient was treated with direct-acting antiviral drugs including Sofosbuvir/ Daclatasvir for twenty weeks. The complete blood count (CBC) and Liver function test (LFT) data were obtained during the whole treatment. The efficacy and safety of treatment was evaluated by CBC and LFT values. The whole data was evaluated by Microsoft excel 2013.

Result: No significant side effect was observed during the whole treatment. The hemoglobin $(\mathrm{Hb})$ level remained normal and did not require additional blood transfusion. The end of therapy response (ETR) was achieved after twenty weeks of treatment.

Conclusion: Sofosbuvir/ Daclatasvir were found effective in the thalassemia patient. There was no need for dose adjustment. The sustained viral response (SVR24) was achieved.

Keywords: Hepatitis C virus infection, $\beta$-thalassemia, HCV genotype-1a, Sofosbuvir/Daclatasvir. 


\section{INTRODUCTION}

Beta thalassemia (autosomal recessive hemoglobinopathy) is one of the most common genetically transmitted disorders worldwide. About 5$7 \%$ of children are carriers of $\beta$-thalassemia in Pakistan [1]. The treatment and survival of thalassemia patients depend on continuous blood transfusion and iron chelation therapy. Consequently, thalassemia patients are susceptible to blood-borne infections, most commonly to hepatitis $B$ virus (HBV) or hepatitis $\mathrm{C}$ virus (HCV) due to frequent blood transfusions. Globally $4.4 \%$ to $85.4 \%$ of thalassemia patients suffer from different genotypes of $\mathrm{HCV}$ infection [2]. Approximately eleven genotypes and several sub-types of HCV have been identified worldwide, out of which only six serotypes $(1,2,3,4$, 5 , and 6) are studied in detail [3]. While in Pakistan, $49 \%$ of the thalassemia patients are suffering from HCV, and most of them have the genotype-1a [4]. Until1991, conventional interferon monotherapy had been used as the only HCV treatment, whereas after 2001, this was replaced by pegylated interferon (Peg IFN) plus Ribavirin [5]. Ribavirin was not recommended for a thalassemic patient due to severe hemolytic effects of the drug [6]. The development of direct-acting antiviral (DAA) agents revolutionized the treatment of HCVinfections. Sofosbuvir, a second-generation DAA, was the first nucleotide-based antagonist of viral polymerase that was approved by the FDA in 2013. Sofosbuvir is a pan-genotype, orally taken once a day, and can be used in combination with other antiviral drugs for the treatment of HCV-infections by genotype 1-4 strains [7]. Interestingly, in some individuals, the solo therapy of Sofosbuvir has shown resistance involving multiple mechanisms [8]. In July 2015, the FDA approved another DAA, i.e., Daclatasvir for use in combination with Sofosbuvir for the treatment of all HCV genotypes [9]. Although, DAAs are known to exhibit side effects such as fatigue, nausea, headache, and insomnia [10], the Sofosbuvir/ Daclatasvir combination therapy has not demonstrated any side effect in thalassemia major patients to the best of our knowledge. Here we are reporting the treatment of HCV genotype-1a infection by Sofosbuvir / Daclatasvir combination therapy in a child having thalassemia major.

\section{CASE REPORT}

A 7- years old boy with a body weight of $20 \mathrm{~kg}$ and height of $135 \mathrm{~cm}$, living in an underprivileged part of Lahore, was diagnosed with thalassemia major in 2011, at the age of one month. With a blood group of O-positive $\left(\mathrm{O}+{ }^{\mathrm{ve}}\right)$, his blood report is tabulated in Table 1. He remained on routine blood transfusions since the time of diagnosis.

In January 2018, he was diagnosed with HCV infection with genotype-1a. The viral load was found to be $140,948 \mathrm{IU} / \mathrm{ml}$, as measured by real-time polymerase chain reaction (RT-PCR). He was referred to Mughal Medical Centre (MMC) LahorePakistan by Sundas Foundation (SF) for hepatitis consultation and treatment. The patient was keenly evaluated at MMC. Apart from the generalized body fatigue, the patient did not show any other significant side effect. All the baseline tests were conducted, and treatment was initiated after analyzing all tests. As per guidelines of the European Association for the Study of the Liver (EASL) \& American Association for the Study of Liver Diseases (AASLD), the treatment comprised of a combination of Sofosbuvir $400 \mathrm{mg} /$ Daclatasvir $60 \mathrm{mg}$, once a day orally.

The patient remained on regular follow-ups by SF and MMC for his routine investigations of CBC and LFT parameters. His blood reports were obtained at different times of the treatment, and are given in Table 2. The primary concern was dose adjustment according to body weight and to manage a significant drop in $\mathrm{Hb}$ levels due to thalassemia and antiviral therapy. After regular follow-up, we maintained his $\mathrm{Hb}$, and the patient did not receive extra blood transfusion apart from his regular blood transfusion. At the beginning of therapy, there was a significant drop in transaminase levels, as shown in the Table 2. The transaminase levels raised in 5th month that correlates with the time of blood transfusion and iron chelation therapy. Because after blood transfusion, hemolysis of stored blood cells occurs that also leads the elevated levels of transaminase. After 20 weeks of treatment, PCR confirmed the absence of the virus and reported it as "Not detected." Ultimately, the end of therapy response (ETR) was achieved, and after the end of therapy, sustained viral response (SVR24) was also accomplished. 
Table 1. Blood Report of the Patient at the Age of Three Months. The Data Shows the Markers of Thalassemia.

\begin{tabular}{|c|c|c|}
\hline \multirow{2}{*}{$\mathrm{Hb}$ Electrophoresis } & $\mathrm{HbA2}$ & $2.10 \%$ \\
\hline & $\mathrm{HbF}$ & $97.90 \%$ \\
\hline \multirow{7}{*}{ Blood Count } & $\mathrm{Hb}(\mathrm{g} / \mathrm{dl})$ & 6.6 \\
\hline & Total RBC count (mill/cumm) & 2.85 \\
\hline & $\operatorname{MCV}(\mathrm{fl})$ & 65 \\
\hline & $\mathrm{MCH}(\mathrm{pg})$ & 23.1 \\
\hline & $\mathrm{MCHC}(\mathrm{g} / \mathrm{dl})$ & 35.8 \\
\hline & Platelet count/ cumm & 465000 \\
\hline & TLC/cumm & 20500 \\
\hline \multirow{8}{*}{ RBC morphology } & Microcytosis & ++ \\
\hline & Macrocytosis & + \\
\hline & Hypochromia & ++ \\
\hline & Polychromasia & + \\
\hline & Target cell & + \\
\hline & Tear drops & + \\
\hline & Poikilocytosis & + \\
\hline & Reticulocyte (\%) & 1.00 \\
\hline \multirow{2}{*}{ RFT's } & Creatinine $(\mathrm{mg} / \mathrm{dl})$ & 0.09 \\
\hline & Urea nitrogen(mg/ dl) & 14.9 \\
\hline \multirow{4}{*}{ LFT's } & Total bilirubin(mg/ dl) & 0.96 \\
\hline & $\mathrm{ALT}(\mathrm{U} / \mathrm{L})$ & 163 \\
\hline & AST (U/L) & 107 \\
\hline & Alkaline Phosphate $(\mathrm{U} / \mathrm{L})$ & 178 \\
\hline \multirow{2}{*}{ Blood Glucose } & Glucose random $(\mathrm{mg} / \mathrm{dl})$ & 90 \\
\hline & G6PD de-colorization time (minutes) & 25 \\
\hline \multirow{3}{*}{ Ferritin } & \multirow{3}{*}{ Ferritin (ng/ml) } & 933.54 \\
\hline & & 1467.4 \\
\hline & & 2904 \\
\hline
\end{tabular}

Table 2. The Hematological and Liver Function test Parameters During the Course of HCV Genotype 1a Treatment. The tests were Conducted During $1^{\text {st }}, 2^{\text {nd }}, 3^{\text {rd }}, 4^{\text {th }}$, and $5^{\text {th }}$ Month of the Treatment to Evaluate the Response and any Adverse Effects of the Treatment.

\begin{tabular}{|c|c|c|c|c|c|}
\hline Labs findings & $1^{\text {st }}$ month & $2^{\text {nd }}$ month & $3^{\text {rd }}$ month & $4^{\text {th }}$ month & $5^{\text {th }}$ month \\
\hline $\mathrm{Hb}(\mathrm{g} / \mathrm{dl})$ & 11.9 & 9.5 & 10.6 & 9.9 & 10.4 \\
\hline HCT (\%) & 34.8 & 27.8 & 30.7 & 30 & 31 \\
\hline RBC count (x10 M/ $\mu \mathrm{l})$ & 4.24 & 3.4 & 3.79 & 3.57 & 3.63 \\
\hline MCV (fl) & 82.1 & 81.8 & 81 & 84 & 85.4 \\
\hline $\mathrm{MCH}(\mathrm{pg})$ & 28.1 & 27.9 & 28 & 27.7 & 28.7 \\
\hline $\mathrm{MCHC}(\mathrm{g} / \mathrm{dl})$ & 34.2 & 34.2 & 34.5 & 33 & 33.5 \\
\hline Platelet count $(\times 10 * 3 / \mu \mathrm{l})$ & 265 & 218 & 337 & 368 & 269 \\
\hline $\operatorname{TLC}(\times 10 * 3 / \mu \mathrm{l})$ & 7.5 & 7.9 & 9.2 & 9.2 & 5.9 \\
\hline Total bilirubin (mg/dl) & 1.2 & 1 & 0.6 & 0.8 & 1.2 \\
\hline ALT (U/L) & 175 & 80 & 63 & 69 & 160 \\
\hline AST (U/L) & 104 & 71 & 50 & 46 & 100 \\
\hline Alkaline phosphate (U/L) & 446 & 419 & 434 & 417 & 315 \\
\hline
\end{tabular}




\section{DISCUSSION}

The treatment of HCV infection in thalassemia major patients is critical. Because, due to iron chelation therapy and increasing viral load, there is a risk of liver cirrhosis or hepatocellular carcinoma. Previously, such patients were treated with interferon monotherapy, which was subsequently replaced by the Pegylated interferon and Ribavirin therapy. The latter therapy was not tolerated by thalassemia patients, resulting in a low SVR rate and severe hemolytic effects $[5,6]$. The DAAs gained importance due to minimum side effects and high SVR rate. In a study, 100 thalassemic patients infected with HCV genotype 1-4 have been treated with Sofosbuvir (SOF) and Ledipasvir (LDV). The same patients were previously treated with Peg IFN/ RBV and had shown inadequate response. The SVR was found $98 \%$ with SOF/LDV and $48 \%$ with Peg IFN/RBV. Some side effects like fatigue, headache, nausea, vomiting, and reduced hemoglobin or increased ferritin levels were observed in patients treated with SOF/LDV [11]. In another study, HCV infections in thalassemia major patients were treated with Elbasvir/Grazoprevir, and 97.6\% ETR was observed, with no change in hemoglobin level [12]. A study by Leroy et al. reported a significant response of SOF/DAC in HCV infection (genotype 3) with advanced liver disease. The SVR12 was found to $87.5 \%$ in those patients who received treatment for 12 weeks and $92.3 \%$ in those who have taken 16 weeks of therapy [13]. In another study, the thalassemia major patients with $\mathrm{HCV}$ infection were treated with SOF/DAC, and the SVR-12 was found to $98.4 \%$ [14]. In our case-study, HCV infection in a thalassemia major patient of age 7 years was treated with SOF/DAC for 20 weeks. No major side-effects were observed in this patient, and the patient did not require extra blood-transfusion in addition to the routine blood transfusion. Baseline $\mathrm{Hb}$ levels were maintained during therapy, which is a tremendous clinical achievement. Additionally, this regimen helped in achieving SVR-24 in the patient.

\section{CONCLUSION}

SOF/DAC is an effective and well tolerable treatment for thalassemia children affected with HCV genotype $1 a$.

\section{STATEMENT OF ETHICS}

This case study was conducted with an approval from the institutional ethics committee. Written consent form was obtained from the patient for publication of the case report.

\section{DISCLOSURE STATEMENT}

None of the authors has any financial conflicts of interest to declare.

\section{REFERENCES}

1. Ansari SH, Shamsi TS, Ashraf M, et al:: Molecular epidemiology of beta-thalassemia in Pakistan: far reaching implications. International Journal of Molecular Epidemiology and Genetics. 2011; 2(4):403-408.

2. Di Marco V, Capra M, Angelucci E, et al:: Management of chronic viral hepatitis in patients with thalassemia: recommendations from an international panel. Blood. 2010; 116(16):28752883. 10.1182/blood-2009-11-248724.

3. Ali $M$, Idrees $M$, Ali $L$, et al:: Hepatitis $B$ virus in Pakistan: a systematic review of prevalence, risk factors, awareness status and genotypes. Virology Journal. 2011; 8(1):102. 10.1186/1743-422X-8102.

4. Din G, Malik S, Ali I, et al:: Prevalence of hepatitis $C$ virus infection among thalassemia patients: a perspective from a multi-ethnic population of Pakistan. Asian Pacific Journal of Tropical Medicine. 2014; 7S1:S127-133. 10.1016/S19957645(14)60218-2.

5. Hamid S, Umar M, Alam A, et al.: PSG consensus statement on management of hepatitis $C$ virus infection--2003. JPMA The Journal of the Pakistan Medical Association. 2004; 54(3):146-150.

6. Ancel D, Amiot X, Chaslin-Ferbus D, et al.: Treatment of chronic hepatitis $\mathrm{C}$ in sickle cell disease and thalassaemic patients with interferon and Ribavirin. European Journal of Gastroenterology \& Hepatology. 2009;21(7):726729. 10.1097/MEG.0b013e3283097699.

7. Jacobson IM, Gordon SC, Kowdley KV, et al:: Sofosbuvir for hepatitis C genotype 2 or 3 in patients without treatment options. The New England Journal of Medicine.2013;368(20):18671877. 10.1056/NEJMoa1214854.

8. Donaldson EF, Harrington PR, O'Rear JJ, et al.: Clinical evidence and bioinformatics 
characterization of potential hepatitis $\mathrm{C}$ virus resistance pathways for sofosbuvir. Hepatology. 2015; 61(1):56-65. 10.1002/hep.27375.

9. Welzel TM, Petersen J, Herzer K, et al:: Daclatasvir plus sofosbuvir, with or without Ribavirin, achieved high sustained virological response rates in patients with HCV infection and advanced liver disease in a real-world cohort. Gut. 2016;65(11):1861-1870. 10.1136/gutjnl-2016312444.

10. Hessel MH, Cohen AF, Rissmann R: Sofosbuvir and daclatasvir. British Journal of Clinical Pharmacology. 2016;82(3):878-879. 10.1111/bcp.13011.

11. Mangia A, Sarli $R$, Gamberini $R$, et al:: Randomised clinical trial: sofosbuvir and ledipasvir in patients with transfusion-dependent thalassaemia and HCV genotype 1 or 4 infection. Alimentary Pharmacology \& Therapeutics. 2017; 46(4):424-431. 10.1111/apt.14197.
12. Hezode $\mathrm{C}$, Colombo $\mathrm{M}$, Bourliere $\mathrm{M}$, et al:: Elbasvir/Grazoprevir for Patients With Hepatitis C Virus Infection and Inherited Blood Disorders: A Phase III Study. Hepatology. 2017; 66(3):736-745. 10.1002/hep.29139.

13. Leroy $\mathrm{V}$, Angus $\mathrm{P}$, Bronowicki JP, et al:: Daclatasvir, sofosbuvir, and ribavirin for hepatitis $\mathrm{C}$ virus genotype 3 and advanced liver disease: $A$ randomized phase III study (ALLY-3+). Hepatology. 2016; 63(5):1430-1441. 10.1002/hep.28473.

14. Zamani F, Ajdarkosh $H$, Safarnezhad-Tameshkel $\mathrm{F}$, et al.: The effectiveness of sofosbuvir and daclatasvir in the treatment of hepatitis $C$ in thalassaemia major patients and their effect on haematological factors. Indian journal of medical microbiology. 2018, 10.4103/ijmm.IJMM_18_90.
36(2):224-229. 